\title{
Un acercamiento \\ a la enseñanza y el aprendizaje de la literatura \\ en el Bachillerato Internacional
}

Ilse Díaz Márquez

$\mathrm{E}$

ntre reformas, evaluaciones e intereses particulares, el desarrollo de una conciencia crítica que permita dar un verdadero giro cultural y económico al país, parece cada vez más lejana y la crisis de las humanidades en la educación mexicana se agudiza. El caso de la Educación Media Superior (EMS) es paradigmático. Puesto que se trata de un nivel preuniversitario, debe ser allí donde los adolescentes se vuelvan más reflexivos en lo que respecta a sí mismos y a su entorno, problematizándolo con el fin de transformarlo. Es en este sentido que las humanidades cumplen un papel irremplazable, pues proporcionan a los jóvenes las herramientas necesarias para iniciar estos procesos que luego tendrán continuación en los estudios superiores y en la vida profesional.

A pesar de todo esto, la ems ha sufrido en los últimos años la eliminación sistemática del pensamiento crítico. Experiencias extranjeras exitosas nos ponen ante la nariz las consecuencias de tal medida, irónicamente, no por la similitud sino por la diferencia en los resultados: el tan sonado sistema finlandés, basado en la confianza y en la autonomía de los estudiantes, o la reciente propuesta de los colegios jesuitas, que han abandonado las asignaturas para trabajar de manera interdisciplinaria y más libre en espacios que rompen con los límites del aula tradicional, serían algunas de ellas. Así, en México sigue importando más la disciplina -no referida a la autorregulación o la capacidad de la organización del trabajo, sino a un orden que tira más hacia lo militar-, los resultados en las pruebas estandarizadas, el papeleo que en realidad no alcanza a dar cuenta de lo que se vivió y aprendió durante el semestre o el ciclo, y hasta hace poco, en el nivel básico, el número de palabras que los alumnos pueden leer por minuto, por mencionar sólo algunos ejemplos frente a los cuales el desarrollo de habilidades como la comprensión de textos, la abstracción, el análisis de la realidad social o la capacidad de argumentación, quedan prácticamente fuera de nuestro alcance.

Ante este panorama tan desolador, no deja de ser vital la labor que desempeñan las preparatorias de las universidades autónomas, quienes todavía, y esperemos que largamente, mantienen planes de estudio donde las materias de humanidades, la libre cátedra y la discusión tienen, aunque cada vez más periféricamente, un lugar. Algunas de estas preparatorias han echado mano de experiencias diversas, análogas a las mencionadas antes, bien incorporándolas a su sistema, o bien ofreciendo planes con metodologías de enseñanza-aprendizaje alternas.

La Universidad Autónoma de Aguascalientes (UAA) imparte, desde finales de la década de 1990, de manera paralela a su plan de estudios, el programa del Diploma del Bachillerato Internacional (BI), al cual los estudiantes del bachillerato tradicional pueden tener acceso, con el correspondiente proceso de admisión a partir del tercer semestre. El programa, diseñado y ofrecido a escuelas y colegios de todo el mundo por la Organización del Bachillerato Internacional (IBO por 
sus siglas en inglés) tiene un duración de dos años y tiene como meta: "formar jóvenes solidarios, informados y ávidos de conocimiento, capaces de contribuir a crear un mundo mejor y más pacífico, en el marco del entendimiento mutuo y el respeto intercultural" (BI, 2013: 5).

El currículo del programa se representa con un hexágono en el centro del cual se encuentran las asignaturas de Teoría del Conocimiento, Monografía y Creatividad, Acción y Servicio, que fungen como eje articulador del resto de las disciplinas, pues desarrollan las capacidades teóricas, de investigación y de colaboración en la comunidad. Alrededor de éstas hay seis grupos de asignaturas: Estudios de Lengua y Literatura, Adquisición de Lenguas, Individuos y Sociedades, Ciencias Experimentales, Matemáticas e Informática y Artes. Cada colegio o escuela, siempre que imparta las tres materias del centro y que cumpla con los otros seis grupos, basará la oferta de asignaturas en sus posibilidades, cultura e ideario educativo, aunque ateniéndose a la lista que proporciona la IBO y a la guía que ésta misma otorga para cada asignatura: un colegio podría decidirse por impartir Química y otro por Biología para el grupo de Ciencias Experimentales dependiendo del perfil de sus profesores, por ejemplo.

Esta disposición del currículo permite a las escuelas administrar de manera flexible sus recursos humanos y materiales, y también que los profesores den un seguimiento riguroso al aprendizaje de sus alumnos, ya que los acompañan a lo largo de los dos años del programa y, además de impartir los temas del programa de materia que cada uno elaboró de acuerdo a su guía y a sus propios criterios y conocimientos, preparan a los chicos para la presentación de las pruebas finales externas, que se envían a algún otro de los países donde la IBO tiene presencia, para que sean evaluadas por examinadores de la misma área. En este punto, los alumnos ya han obtenido el certificado de EMS que expide la Secretaría de Educación Pública, pues nunca deja de evaluárseles de manera interna; sin embargo, si sus resultados externos son favorables, recibirán el diploma que otorga la IBO, mismo que da a su formación un reconocimiento internacional y que en algunos casos les concede acceso a universidades extranjeras.

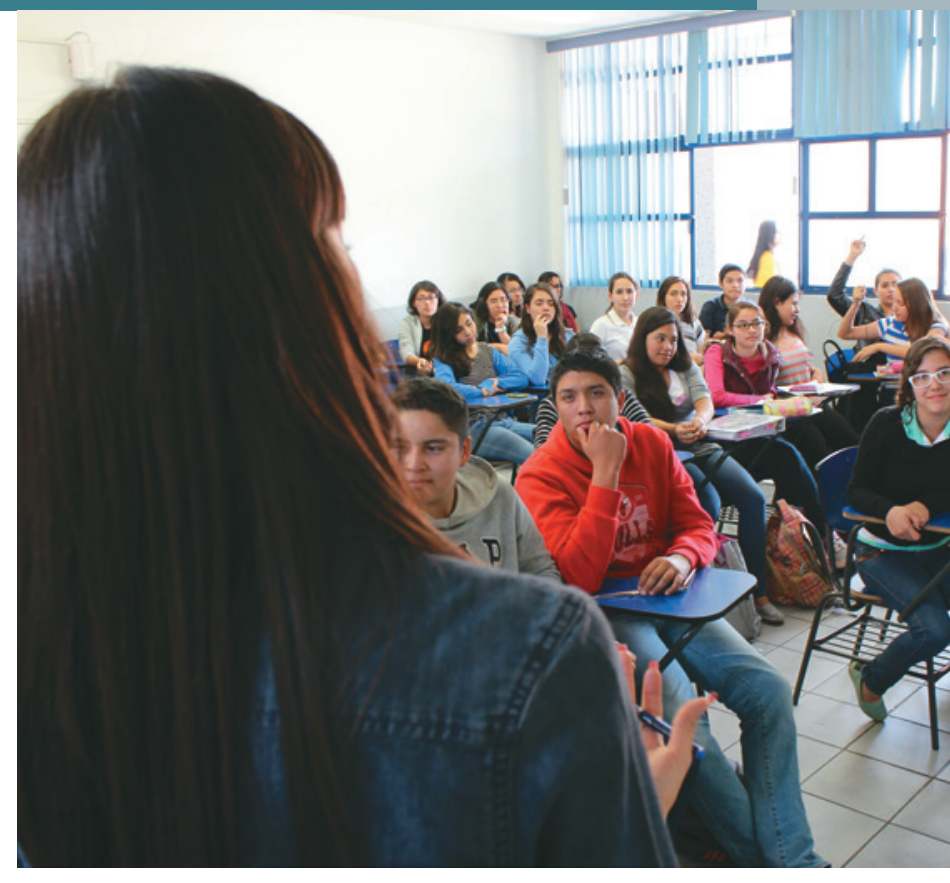

Otras de las particularidades del Bi que resultan interesantes es precisamente el énfasis que hace en el desarrollo de las habilidades de análisis y crítica con una práctica pedagógica constructivista, la atención más personalizada a los estudiantes ya que se trabaja con grupos pequeños -entre 20 y 25 alumnos en el caso de la UAA-, así como la puesta en práctica del aprendizaje autónomo y de la indagación a lo largo de todo el programa. Los profesores del BI tienen la libertad de elegir las metodologías más adecuadas a su asignatura, siempre y cuando no contradigan la filosofía básica planteada por el programa.

La asignatura de Literatura, dentro y fuera del sistema del BI, funge como una de las principales promotoras de este pensamiento crítico al que me he venido refiriendo. Como declara la guía de la asignatura del вI (2013:5):

[...] la literatura refleja nuestras concepciones, interpretaciones y experiencias del mundo. Por lo tanto, el estudio de la literatura puede considerarse una exploración de la forma en que representa las complejas búsquedas, ansiedades, alegrías y temores a los que están expuestos los seres humanos día a día. Permite la exploración de uno de los campos más perdurables de la creatividad humana y brinda oportunidades para estimular el pensamiento independiente, original, crítico y claro. 
El BI desatiende la forma clásica de enseñar literatura, la cual toma como línea conductora las épocas y las corrientes, con sus rasgos y características, lo que en ocasiones deriva en un excesivo énfasis en los nombres de los autores, en sus biografías y en los títulos de sus obras, dejando en segundo o tercer plano la médula de los estudios literarios que no es otra sino la interpretación de los textos, o bien restringiéndola a un comentario superficial.

En el BI, las obras literarias que se estudian son dos terceras partes pertenecientes a la lengua materna de los estudiantes, y una tercera parte traducciones de obras en otras lenguas; se analizan tomando siempre en cuenta sus contextos culturales, y se ordenan de acuerdo con unos lineamientos mínimos que no impiden que el profesor termine de organizarlas de la manera que considere más adecuada, sea cronológica, temática o de otra naturaleza. Lo que complementa este ordenamiento, y desde mi punto de vista, lo más importante es la necesidad de abordar las obras desde diversos enfoques críticos, tanto en su dimensión formal y estética -la técnica, el estilo, el lenguaje-, como en toda su complejidad filosófica, sociológica e histórica, permitiendo la exploración de diferentes formas de interpretación e incluso la utilización de nociones básicas de teoría literaria. De esta forma, los estudiantes no se quedan en la superficie de la obra, ni aprenden de memoria una serie de tópicos o rasgos, sino que aplican constantemente los conceptos en el análisis y conectan éste con su propia experiencia de la lectura, del mundo que les rodea, que es el de su cultura, y también con otras visiones de la realidad.

A partir de mi experiencia como profesora de la asignatura de Literatura en el BI, destaco el trabajo de selección de obras, que siempre implica la eliminación de textos que una quisiera incluir, y sobre todo una reflexión constante de la pertinencia de aquellos que sí se trabajan. Ligado a ello, está la búsqueda de los enfoques adecuados y de cada una de las actividades que irán acompañando a los análisis: trabajo en grupo o individual, investigación, exposición, etc. Metodologías que todo profesor conoce y que no implican una verdadera novedad, pero que deben estar atravesadas siempre por una voluntad de cuestionamiento y de discusión, ante lo cual se vuelve fundamental aprender a formular las preguntas de la manera más adecuada posible, y al mismo tiempo, empatar en las premisas de aná- lisis la parte técnica y la parte reflexiva, tratando siempre de llevar más allá de la primera impresión a los alumnos. Finalmente, la retroalimentación intensiva durante el diálogo en el aula, que es insustituible, y a la vez con comentarios y asesorías sobre los trabajos escritos.

Para los estudiantes, también desde mi observación y experiencia, la relación con los textos se va volviendo gradualmente más cercana, y les da la oportunidad de ir conformando categorías personales y de tomar conciencia de su vocación de lectores. Les permite, de la misma forma y en conjunto con otras asignaturas, argumentar para defender sus puntos de vista, sensibilizarse respecto a situaciones muy diversas sin adoptar puntos de vista compasivos, y volverse sujetos intelectualmente inquietos. Asimismo, en el campo de la escritura, que por lo general es aún más ardua que la lectura, la asignatura les impulsa a tomar decisiones temáticas y de interpretación, y les exige un esfuerzo constante de ordenamiento y manifestación de ideas; es acerca de este proceso que culmina en la redacción de un ensayo y en la presentación de dos pruebas, que los alumnos suelen comentar que han visto la diferencia entre sus primeras críticas y los trabajos finales, apreciación que resulta la mayoría de las veces positiva.

Desde una práctica pedagógica que desea ser liberadora y no limitante, la alternativa del BI y el caso concreto del estudio de la literatura, aparecen como oportunidades para impulsar a los jóvenes a la transformación de su realidad, como señalé al inicio, y no a la repetición de esquemas de sujeción. La pregunta que ahora como docentes nos corresponde plantear y comenzar a responder es cómo incorporar este tipo de prácticas, que no dejan de tener un cierto carácter elitista debido a que pocos jóvenes tienen acceso a ellas, a nuestros sistemas nacionales, adecuándolas a los contextos en los que trabajamos, y volviéndonos también sujetos activos en las dinámicas de cambio.

\section{Fuente de consulta}

Bachillerato Internacional. (2013). Programa del Diploma. Guía de Lengua A: Literatura. Reino Unido: Organización del Bachillerato Internacional. 